Check for updates

Cite this: RSC Adv., 2018, 8, 7873

\title{
Preparation of magnesium silicate/carbon composite for adsorption of rhodamine $\mathrm{B} \uparrow$
}

\begin{abstract}
Zhiwei Sun, (DD ${ }^{\text {ab }}$ Xinhui Duan, ${ }^{\text {ab }}$ C. Srinivasakannan ${ }^{c}$ and Jinsheng Liang*ab
A magnesium silicate/carbon composite was prepared by a simple hydrothermal method using sodium silicate, magnesium sulfate, glucose and sodium acetate as raw materials. The composite was characterized using Fourier transform infrared spectroscopy (FT-IR), X-ray diffraction (XRD), scanning electron microscopy (SEM) and BET to understand the morphological and chemical changes. It was found that the composite was composed of amorphous magnesium silicate and amorphous hydrothermal carbon with a layered porous structure and a specific surface area of $235 \mathrm{~m}^{2} \mathrm{~g}^{-1}$. Rhodamine $\mathrm{B}(\mathrm{RhB})$ was used as a simulated contaminant in water to assess the adsorption properties of the composite. The equilibrium adsorption capacity of the composite was found to be $244 \mathrm{mg} \mathrm{g}^{-1}$, $27.48 \%$ higher than that of magnesium silicate. The adsorption of RhB onto the composite was affected by $\mathrm{pH}$ of the solution with the highest adsorption capacity corresponding to a $\mathrm{pH}$ of 9 . The adsorption kinetics of RhB onto the composite could be better described by a pseudo second-order model. The adsorption process was found to be controlled by intraparticle-diffusion. The adsorption isotherm data matched better with that of the Langmuir model, confirming monolayer adsorption on the homogeneous surface. In view of its good adsorption capacity, the adsorbent prepared in this study has the potential of treating dye wastewater in practical applications.
\end{abstract}

Received 28th November 2017

Accepted 31st January 2018

DOI: $10.1039 / \mathrm{c} 7 \mathrm{ra12848g}$

rsc.li/rsc-advances dye wastewater has the advantages of no chemical addition, simple post-processing, small footprint and easy management; however, it demands large power consumption and the usage of large electrode materials, which limits its application. ${ }^{15}$ On the contrary, adsorption is widely utilized due to the advantages of large adsorption capacity, simple processing and environmentfriendliness and has proved to be an effective method for the treatment of dye wastewater. ${ }^{\mathbf{1 6 , 1 7}}$ Commonly used adsorbents include activated carbon, polymer adsorbents and silicate. Compared with burgeoning adsorbents, activated carbon has the best adsorption capacity, but it is not economic. ${ }^{18}$ Polymer adsorbents have excellent adsorption capacity towards metal ions, but their ability to remove organic dyes is poor. ${ }^{19}$ Silicates have the advantages of rich content, eco-friendliness and inexpensiveness and are suitable for use as adsorbents. ${ }^{20-22}$

Magnesium silicates can potentially adsorb cationic dyes because of their large surface area and surfaces rich with hydroxyl groups. ${ }^{\mathbf{2 3 , 2 4}}$ The research community has recently become interested in composite materials since they often possess excellent properties, which are superior to the virgin component they are made of. ${ }^{25,26}$ This initiated the idea to prepare a silicate-based composite for wastewater treatment applications. Recent literature reveals efforts on preparation of composite materials by a number of researchers. Zhang et al. ${ }^{27}$ prepared a composite using activated carbon/palygorskite, which had a methylene blue adsorption capacity of $351 \mathrm{mg}$ $\mathrm{g}^{-1}$, far superior than either of the individual materials. Cheng
${ }^{a}$ Key Laboratory of Special Functional Materials for Ecological Environment and Information, Hebei University of Technology, Ministry of Education, Tianjin 300130, China. E-mail: liangjinsheng@hebut.edu.cn

${ }^{b}$ Institute of Power Source and Ecomaterials Science, Hebei University of Technology, Tianjin 300130, China

${ }^{c}$ Chemical Engineering Department, Khalifa University of Science and Technology, The Petroleum Institute, Abu Dhabi, United Arab Emirates

$\dagger$ Electronic supplementary information (ESI) available. See DOI: $10.1039 / \mathrm{c} 7 \mathrm{ra12848g}$ 
et $a{ }^{28}$ synthesized graphene oxide/silicalite-1 composite by a hydrothermal method and reported an $\mathrm{RhB}$ adsorption

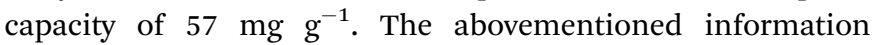
confirms the superiority of the composite materials and demands further investigation in this direction. The hydrothermal method is an advanced method for the synthesis of functional materials. It is a chemical reaction carried out at high temperature and pressure in a closed container and in an aqueous reaction medium. Hydrothermal carbon is a kind of black solid product with the main body made of carbon rich in oxygen functional groups and having a high calorific value. However, due to low porosity and density, its application to liquid phase is limited due to filtration issues. ${ }^{29}$ Recent literature has revealed that the composites of hydrothermal carbon and silicate have high density and large surface area, which could be suitable for wastewater treatment applications. ${ }^{28,30}$

Hence, to develop an effective organic dye adsorbent and to fully utilize the abundant silicate and biomass resources in nature, a magnesium silicate/carbon composite was successfully prepared utilizing glucose (as carbon source), sodium acetate (to introduce carboxyl groups) and magnesium silicate by a simple one-step hydrothermal method. The structure and properties of the composite were characterized utilizing a number of well-established analytical methods and tested for the composite's adsorption capacity towards $\mathrm{RhB}$. The results showed that the prepared composite possesses a large specific surface area (compared to hydrothermal carbon), rich functional groups (compared to magnesium silicate) and excellent $\mathrm{RhB}$ adsorption properties, making it an excellent wastewater treatment adsorbent.

\section{Experiments}

\subsection{Materials}

Sodium silicate $\left(\mathrm{Na}_{2} \mathrm{SiO}_{3} \cdot 9 \mathrm{H}_{2} \mathrm{O}\right)$, magnesium sulfate $\left(\mathrm{MgSO}_{4}{ }^{-}\right.$ $\cdot 7 \mathrm{H}_{2} \mathrm{O}$ ) and anhydrous sodium acetate were purchased from Bodi Chemical Co. Ltd. (Tianjin, China). Glucose and RhB were purchased from Fengchuan chemical reagent technology Co. Ltd. (Tianjin, China). All the abovementioned materials and other reagents used were of analytical grade. The water used was deionized water.

\subsection{Synthesis of magnesium silicate/carbon composite}

$2 \mathrm{~g}$ ( 0.0070 moles $)$ of sodium silicate, $0.5 \mathrm{~g}$ ( 0.0028 moles $)$ of glucose and $0.05 \mathrm{~g}$ ( 0.0006 moles) of sodium acetate were dissolved in $40 \mathrm{~mL}$ of deionized water under constant magnetic stirring. Then, $20 \mathrm{~mL}$ of aqueous solution containing $3.47 \mathrm{~g}$ (0.0140 moles) magnesium sulfate (the $\mathrm{Si} / \mathrm{Mg}$ molar ratio is $1: 2$, which corresponds to the optimal adsorption capability towards RhB, Fig. S1†) was added dropwise into the abovementioned solution. The mixture was continuously stirred for another $30 \mathrm{~min}$. Then, the mixture was placed in a $100 \mathrm{~mL}$ Teflon-lined stainless steel autoclave, sealed, and reacted at 200 ${ }^{\circ} \mathrm{C}$ for $4 \mathrm{~h}$. After the reactor cooled to room temperature, the hydrothermal reaction product was washed with deionized water to remove the residual free ions and dried at $80^{\circ} \mathrm{C}$ for $12 \mathrm{~h}$ in an oven. The dried product was ground and passed through a 200-mesh sieve to obtain a magnesium silicate/carbon composite. A contrast between the processes of preparing magnesium silicate and glucose hydrothermal carbon is as following: the preparation process of magnesium silicate was the same as that of the composite except that the addition of glucose and sodium acetate was not required. In the preparation process of hydrothermal carbon, $3 \mathrm{~g}$ ( 0.0167 moles) of glucose was dissolved in $60 \mathrm{~mL}$ of deionized water, and the solution was placed in an autoclave. The rest of the process was the same as that of the composite.

\subsection{Characterization}

$\mathrm{X}$-ray diffraction analysis was performed using an X-ray diffractometer with a $\mathrm{Cu}$ anode operating at $40 \mathrm{kV}$ and 100 $\mathrm{mA}$ (XRD, D8 Advanced Bruker). The microstructure was analyzed using a Scanning Electron Microscope (SEM, Nova Nano SEM450, FEI). The Fourier transform infrared spectroscopy spectra were obtained on a V80 Fourier transform infrared spectrometer using KBr pellets (FT-IR, Bruker). The BET surface area and pore size distribution were estimated using a physical adsorption instrument (Autosorb IQ, Quantachrome). The isoelectric point was determined by a potential analyzer (NanoZS90, Marvin).

\subsection{Adsorption of $\mathrm{RhB}$}

To evaluate the adsorption capacity of the composite, different initial concentrations (50-600 $\mathrm{mg} \mathrm{L}^{-1}$ ) of RhB aqueous solutions were prepared. The adsorption studies were carried out with $0.1 \mathrm{~g}$ composite introduced into $100 \mathrm{~mL} \mathrm{RhB}$ aqueous solution at an initial concentration of $50-600 \mathrm{mg} \mathrm{L}^{-1}$. The adsorption experiments were carried out at a constant temperature in a shaker bath at $180 \mathrm{rpm}$. After the adsorption, the RhB solution was centrifuged and the filtrate was separated, and its absorbance was measured with a visible spectrophotometer at a wavelength of $554 \mathrm{~nm}$. The concentration of the remaining RhB solution was calculated and the concentration was utilized to estimate the adsorption capacity of the adsorbent $q_{\mathrm{e}}\left(\mathrm{mg} \mathrm{g}^{-1}\right)$ for RhB using a simple mass balance eqn (1).

$$
q_{\mathrm{e}}=\frac{\left(C_{0}-C_{\mathrm{e}}\right) V}{M}
$$

where $C_{0}$ and $C_{\mathrm{e}}$ are the initial and equilibrium concentrations of RhB solutions ( $\left.\mathrm{mg} \mathrm{L}^{-1}\right)$, respectively. $V$ is the volume of solution (L) and $M$ is the weight of adsorbents ( $\mathrm{g}$ ).

The amount of adsorption $q_{t}\left(\mathrm{mg} \mathrm{g}^{-1}\right)$ by adsorbents at time ' $t$ ' was calculated by the following equation (eqn (2)):

$$
q_{t}=\frac{\left(C_{0}-C_{t}\right) V}{M}
$$

where $C_{0}$ and $C_{t}$ are the $\mathrm{RhB}$ concentrations $\left(\mathrm{mg} \mathrm{L}^{-1}\right)$ at an initial and pre-determined time $t\left(\mathrm{mg} \mathrm{L}^{-1}\right)$, respectively. $V$ is the volume of solution (L) and $M$ is the weight of the adsorbents (g).

To evaluate the adsorption capacity of the composite at different $\mathrm{pH}$ values, adsorption experiments were carried out in 
the $\mathrm{pH}$ range of 1 to 13 . The $\mathrm{pH}$ of the suspension was adjusted with hydrochloric acid and sodium hydroxide solution. To generate the adsorption kinetic data, the liquid samples were taken at predetermined time intervals from 0.5 to $24 \mathrm{~h}$ at $303 \mathrm{~K}$. The adsorption isotherms were generated by varying the initial concentrations of $\mathrm{RhB}$ with the adsorption temperature and duration being $303 \mathrm{~K}$ and $24 \mathrm{~h}$, respectively. To estimate the adsorption thermodynamic parameters, the adsorption tests were carried out at temperatures of 293, 298, 303, 308 and $313 \mathrm{~K}$. Each adsorption data generated corresponded to an average of the three runs carried out simultaneously under the same conditions. The simultaneous runs ensured repeatability with minimal errors among different samples.

\section{Results and discussion}

\subsection{FT-IR spectra analysis}

The FT-IR spectra of the prepared magnesium silicate (curve A) and magnesium silicate/carbon composite (curve B) are shown in Fig. 1. As shown in curve A, the wide characteristic band in the range of 3700 to $2800 \mathrm{~cm}^{-1}$ (including 3678, 3410, 2928 and $2853 \mathrm{~cm}^{-1}$ ) could be attributed to the $-\mathrm{OH}$ stretching vibration due to physical adsorption of water and bound water. The characteristic band at $1641 \mathrm{~cm}^{-1}$ could be attributed to the stretching vibration of zeolite water. The characteristic bands at $1018 \mathrm{~cm}^{-1}$ and $619 \mathrm{~cm}^{-1}$ corresponded to the Si-O bending vibrations. The characteristic bands at $1108 \mathrm{~cm}^{-1}$ and $916 \mathrm{~cm}^{-1}$ also corresponded to the $\mathrm{Si}-\mathrm{O}$ stretching vibrations. The characteristic band at $459 \mathrm{~cm}^{-1}$ corresponded to the $\mathrm{Mg}-\mathrm{O}$ stretching vibration. The characteristic band appearing at $1420 \mathrm{~cm}^{-1}$ in curve $\mathrm{B}$ corresponded to the $\mathrm{C}-\mathrm{H}$ bending vibration of the hydrothermal carbon. The disappearance of the characteristic band at $1108 \mathrm{~cm}^{-1}$ could be due to the formation of $\mathrm{Si}-\mathrm{O}-\mathrm{C}$ by the combination of the hydrothermal carbon and magnesium silicate, resulting in the disappearance of $\mathrm{Si}-\mathrm{O}$ asymmetric bending vibration. ${ }^{31}$ The characteristic band at $619 \mathrm{~cm}^{-1}$ was transferred to $660 \mathrm{~cm}^{-1}$, which could be due to

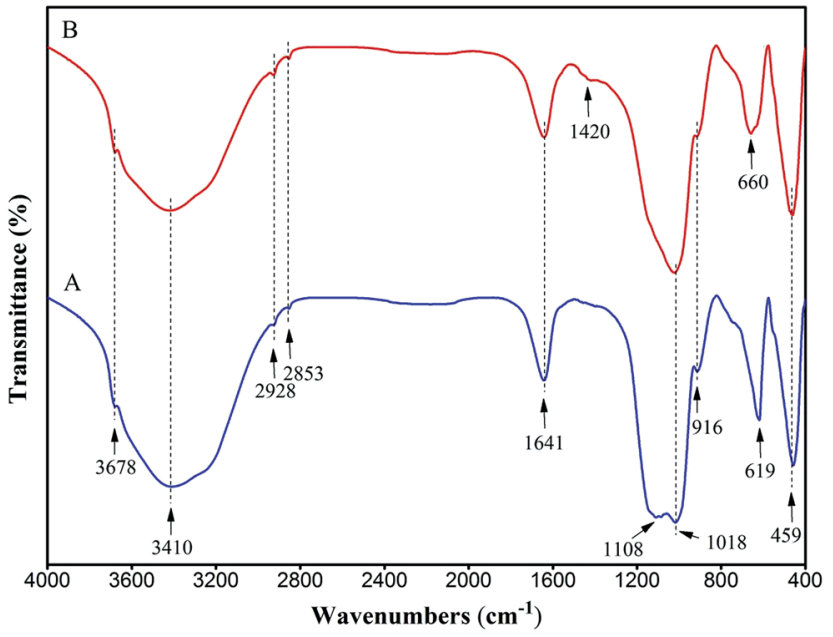

Fig. 1 FT-IR spectra of magnesium silicate (A) and magnesium silicate/ carbon composite (B). the pore of magnesium silicate being blocked by the hydrothermal carbon. The change in FT-IR spectrum proved that the composite of magnesium silicate and hydrothermal carbon was realized. The $-\mathrm{COOH}$ characteristic band was not observed in curve $\mathrm{B}$, due to the characteristic band of $-\mathrm{COOH}$ overlapping with the $\mathrm{Si}-\mathrm{O}$ stretching vibration band at $916 \mathrm{~cm}^{-1} \cdot{ }^{25}$

\subsection{XRD analysis}

The XRD patterns of the prepared magnesium silicate (pattern A), glucose hydrothermal carbon (pattern B) and magnesium silicate/carbon composite (pattern $\mathrm{C}$ ) are illustrated in Fig. 2. The peaks at $2 \theta=20,35$ and $60^{\circ}$ appearing in patterns $\mathrm{A}$ and $\mathrm{C}$ are the diffraction peaks of magnesium silicate (JCPDS file 021009), indicating that the magnesium silicate is present in an amorphous state. The peaks of $2 \theta=19.18$ and $32.30^{\circ}$ in pattern A are the diffraction peaks of the (001) and (101) planes of $\mathrm{Mg}(\mathrm{OH})_{2}$ (JCPDS file 44-1482). This is because the $\mathrm{OH}^{-}$(induced by hydrolysis of sodium silicate) reacts with $\mathrm{Mg}^{2+}$ to form $\mathrm{Mg}(\mathrm{OH})_{2}$. There is only one strong broad peak in the XRD pattern of glucose hydrothermal carbon, which proves that the hydrothermal carbon generated under this condition is amorphous. The diffraction peaks of $\mathrm{Mg}(\mathrm{OH})_{2}$ in pattern A are not found in the XRD pattern of the magnesium silicate/carbon composite, which is due to the weak diffraction peaks of $\mathrm{Mg}(\mathrm{OH})_{2}$ being masked by the strong peaks of amorphous carbon. There are only three weak broad diffraction peaks in pattern $\mathrm{C}$, demonstrating that the composite consists of an amorphous magnesium silicate and amorphous carbon. The amorphous state endows the composite with a high specific surface area, which is helpful to improve the adsorption performance.

\subsection{Morphologies and pore structure analysis}

Fig. 3 shows the SEM images of the prepared magnesium silicate (image A), glucose hydrothermal carbon (image B), magnesium silicate/carbon composite (image C) and the TEM

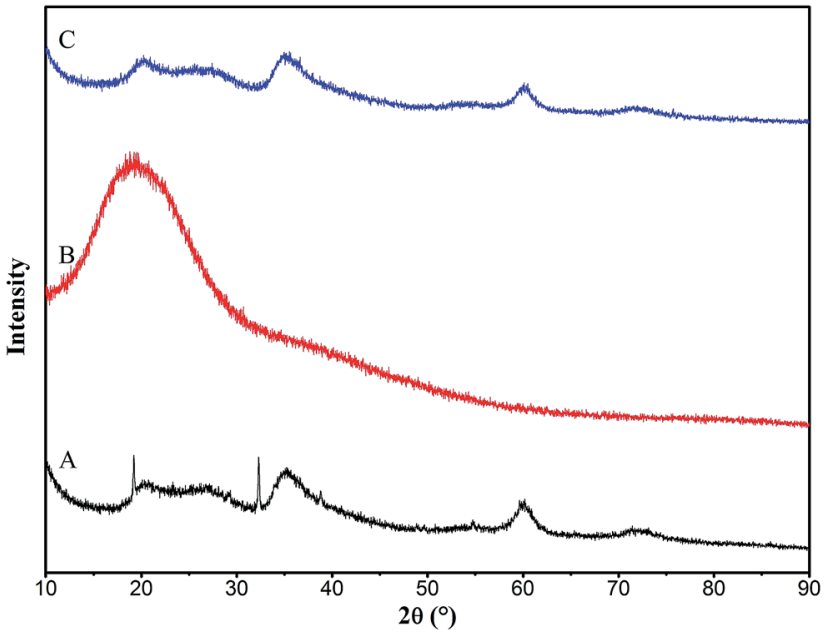

Fig. 2 XRD patterns of magnesium silicate (A), glucose hydrothermal carbon (B) and magnesium silicate/carbon composite (C). 


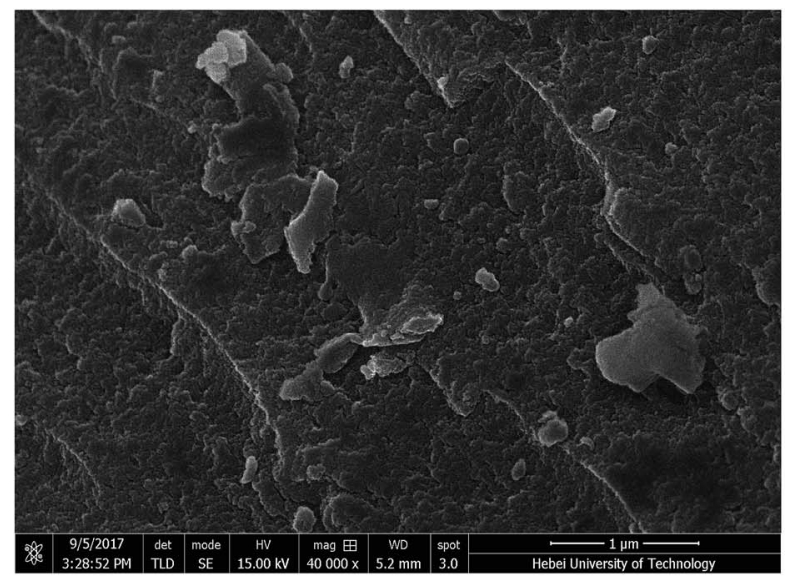

A

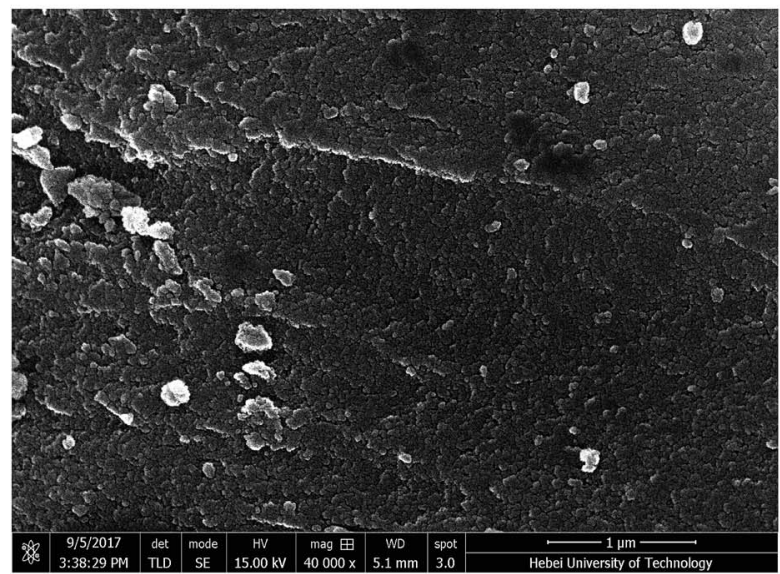

C

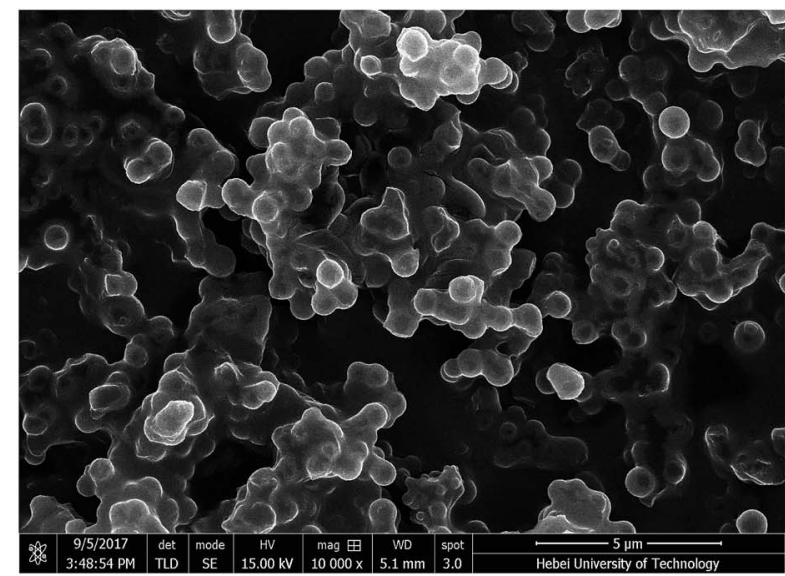

B

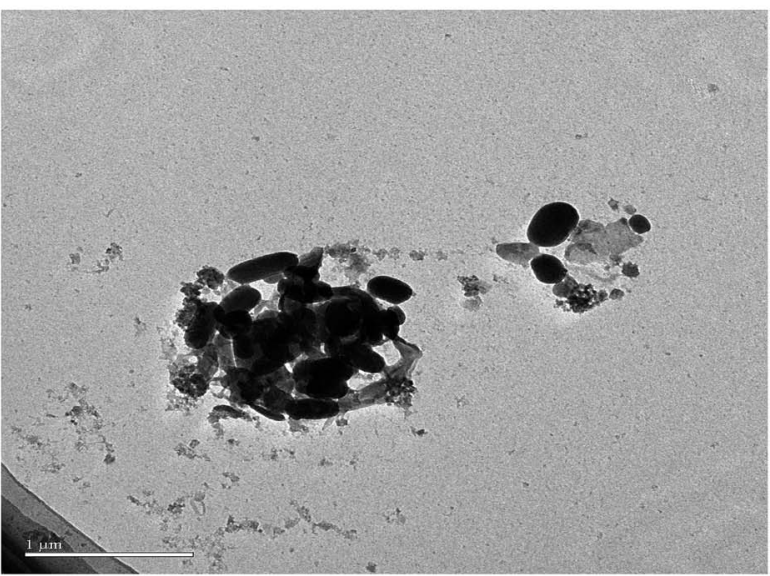

D

Fig. 3 SEM images of magnesium silicate (A), glucose hydrothermal carbon (B), magnesium silicate/carbon composite (C) and TEM image of magnesium silicate/carbon composite (D).

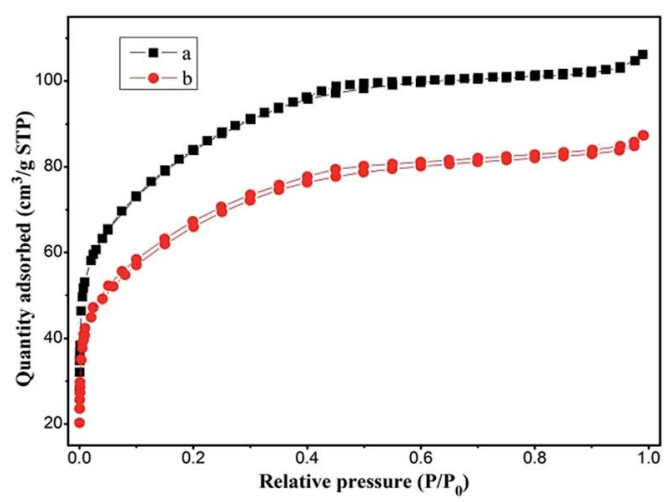

A

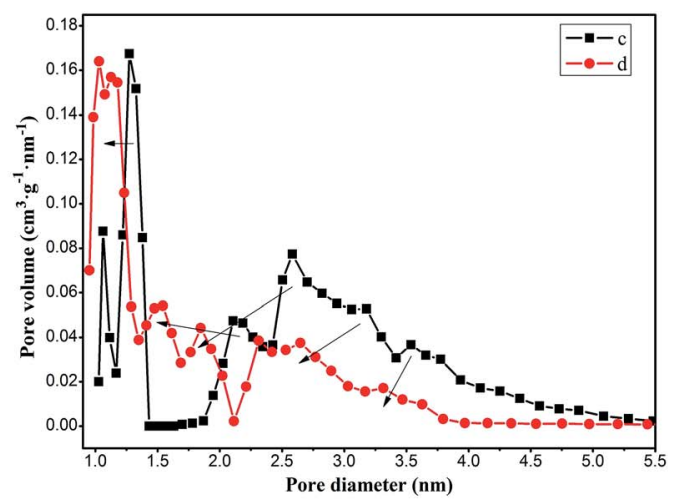

B

Fig. 4 (A) $\mathrm{N}_{2}$ adsorption-desorption isotherms of magnesium silicate (a) and magnesium silicate/carbon composite (b); (B) pore size distribution of magnesium silicate (c) and magnesium silicate/carbon composite (d). 


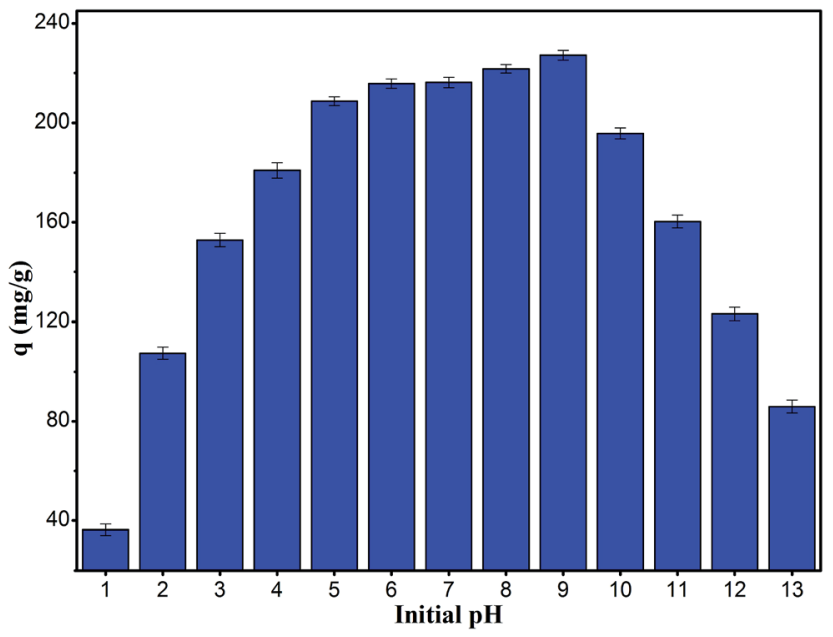

Fig. 5 Influence of $\mathrm{pH}$ value for the adsorption of RhB onto magnesium silicate/carbon composite.

Table 1 The adsorption capacities of other adsorbents for RhB

\begin{tabular}{|c|c|c|}
\hline Adsorbents & $\begin{array}{l}\text { Adsorption capacity } \\
\left(\mathrm{mg} \mathrm{g}^{-1}\right)\end{array}$ & References \\
\hline GE/AC & $256.41 \mathrm{mg} \mathrm{g}^{-1}$ & 33 \\
\hline GB & $64.47 \mathrm{mg} \mathrm{g}^{-1}$ & 34 \\
\hline PDBpc & $328.7 \mathrm{mg} \mathrm{g}^{-1}$ & 35 \\
\hline Polymer nanocomposites & $208 \mathrm{mg} \mathrm{g}^{-1}$ & 36 \\
\hline TA-G & $201.00 \mathrm{mg} \mathrm{g}^{-1}$ & 37 \\
\hline PLA/AC & $149.57 \mathrm{mg} \mathrm{g}^{-1}$ & 38 \\
\hline $\mathrm{NiO}$ & $111 \mathrm{mg} \mathrm{g}^{-1}$ & 39 \\
\hline $\mathrm{SnS}_{2}$ & $200 \mathrm{mg} \mathrm{g}^{-1}$ & 40 \\
\hline
\end{tabular}

image of the magnesium silicate/carbon composite (image D). It can be seen from image $\mathrm{B}$ that the glucose hydrothermal carbon is spherical. The surface morphology of the composite is lamellar and is more developed than that of magnesium silicate. It can be clearly seen from image D that the ellipsoidal hydrothermal carbon and the irregularly shaped magnesium silicate were compounded.

Fig. 4A shows the $\mathrm{N}_{2}$ adsorption-desorption isotherm of magnesium silicate (curve a) and magnesium silicate/carbon composite (curve b), which resembles a type IV isotherm according to the IUPAC classification. It is characterized by a rapid increase in the amount of $\mathrm{N}_{2}$ adsorption up to a relative pressure $P / P_{0}$ of 0.1 and a progressive increase beyond that. This kind of isotherm corresponds to materials with a mixture of micro and mesopores but with a relatively large proportion of micropores. The microporous volume of magnesium silicate and the composite account for $74.07 \%$ and $78.66 \%$ of the total pore volume, respectively. Fig. $4 \mathrm{~B}$ shows the pore size distribution of magnesium silicate (curve c) and the composite (curve d). As is shown in the figure's arrow, the pore size of the composite is smaller than that of magnesium silicate. The average pore diameters of magnesium silicate and the composite are $2.30 \mathrm{~nm}$ and $2.20 \mathrm{~nm}$, respectively. Based on the $\mathrm{N}_{2}$ adsorption-desorption isotherm, the specific surface area and pore volume are estimated as $235.30 \mathrm{~m}^{2} \mathrm{~g}^{-1}$ and $0.135 \mathrm{~cm}^{3}$ $\mathrm{g}^{-1}$ for the composite, respectively, whereas those for the magnesium silicate are $297.90 \mathrm{~m}^{2} \mathrm{~g}^{-1}$ and $0.164 \mathrm{~cm}^{3} \mathrm{~g}^{-1}$, respectively. The reduction in the surface area and the pore volume of the composite can be attributed to the small size of the carbon particles blocking the pores of magnesium silicate. However, the adsorption capacity of RhB onto the composite is higher than that of magnesium silicate, which indicates that the

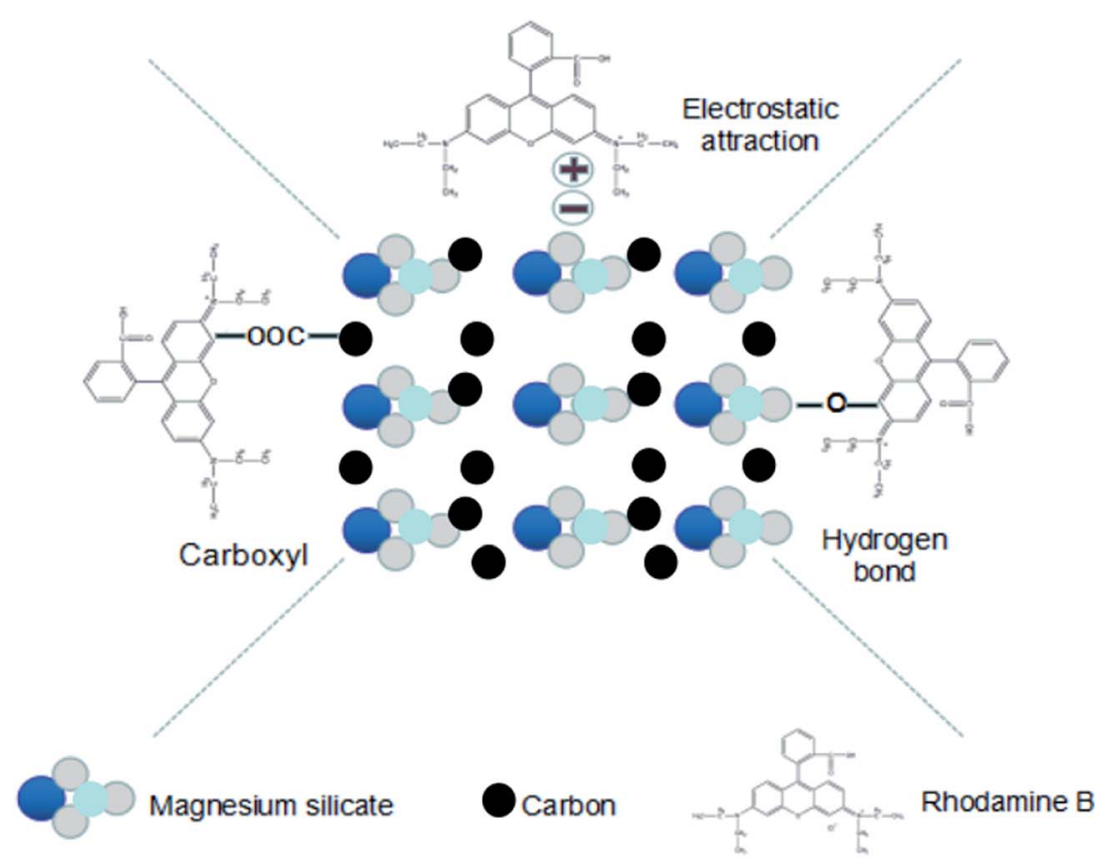

Fig. 6 Schematic illustration of the mechanisms for the adsorption of RhB onto magnesium silicate/carbon composite. 
specific surface area is not the only factor that determines the adsorption performance.

\subsection{Effect of the initial $\mathrm{pH}$ on adsorption of rhodamine $\mathrm{B}$}

It is useful to know the adsorption capacity of the composite at different $\mathrm{pH}$ values for practical applications. ${ }^{32}$ Fig. 5 shows the equilibrium adsorption capacity of the composite for $\mathrm{RhB}$ at a concentration of $400 \mathrm{mg} \mathrm{L}^{-1}$ and $\mathrm{pH}$ ranging from 1 to 13 . The adsorption capacity increased drastically with increase in $\mathrm{pH}$ from 1 to 5 , whereas at $\mathrm{pH}$ values higher than 5 and up to 9 , the increase was marginal $\left(>200 \mathrm{mg} \mathrm{g}^{-1}\right)$. However at a $\mathrm{pH}$ higher than 10, the adsorption capacity decreased drastically. The response with respect to $\mathrm{pH}$ could be related to the isoelectric point. When the $\mathrm{pH}$ was lower than the isoelectric point of 1.23, the composite was positively charged, which repelled the

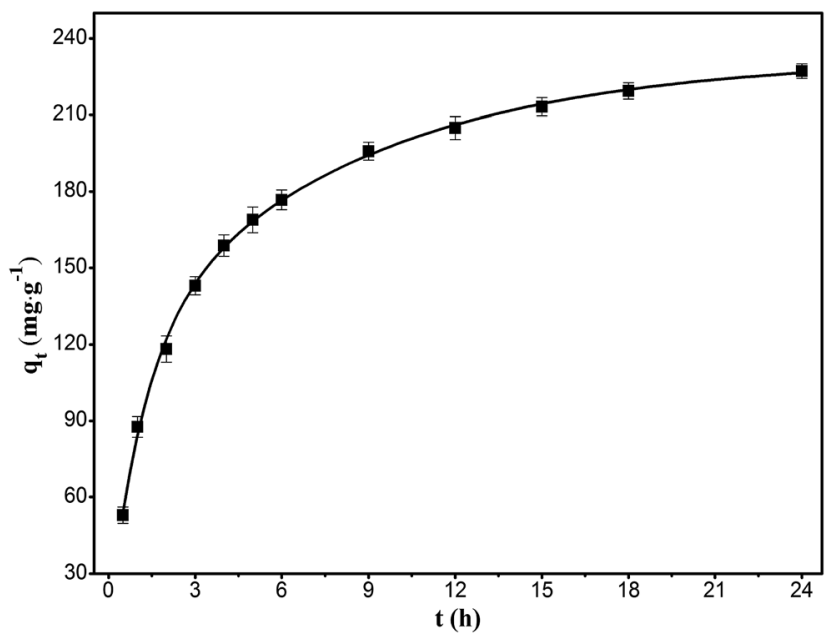

Fig. 7 Kinetics of the adsorption of RhB onto magnesium silicate/ carbon composite.

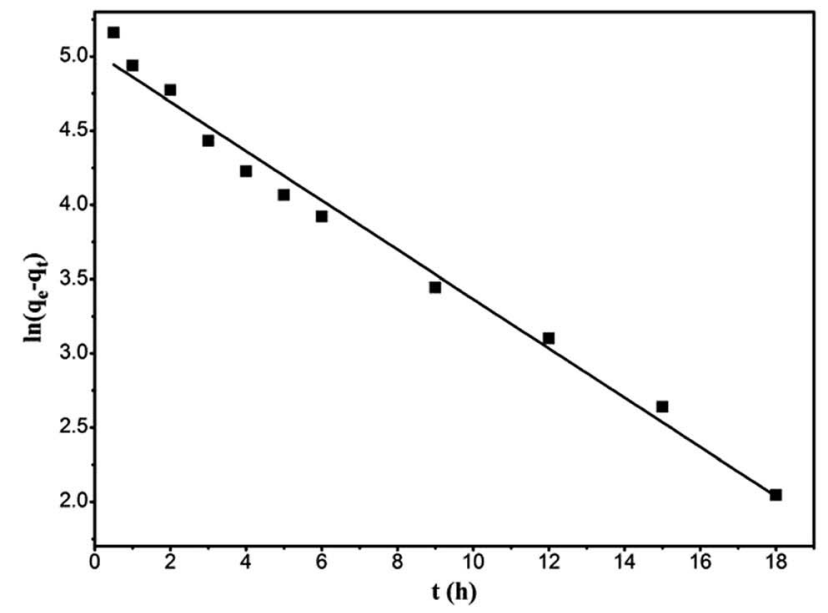

A chromogenic group of the cationic dye RhB; this was not conducive to adsorption. On the contrary, when the $\mathrm{pH}$ was higher than the isoelectric point, the composite was negatively charged, which was favorable for adsorption. However, when the $\mathrm{pH}$ continued to increase, the $\mathrm{RhB}$ molecular surface became negatively charged, resulting in electrostatic repulsion with the composite and hence, a decrease in the adsorption capacity of RhB was observed. In addition, high concentrations of chloride ions at low $\mathrm{pH}$ and sodium ions at high $\mathrm{pH}$ generated competitive adsorption with RhB, which was another factor leading to low adsorption.

\subsection{Adsorption capacity}

The adsorption capacity of the magnesium silicate/carbon composite for RhB was evaluated at $303 \mathrm{~K}$ and was found to be $244 \mathrm{mg} \mathrm{g}^{-1}$, which was nearly $28 \%$ higher than that of magnesium silicate $\left(191 \mathrm{mg} \mathrm{g}^{-1}\right)$. The $-\mathrm{COOH}$ produced by sodium acetate successfully grafted on hydrothermal carbon (strong $-\mathrm{COOH}$ characteristic band at $1703 \mathrm{~cm}^{-1}$ of glucose hydrothermal carbon added to sodium acetate, Fig. S2 $\dagger$ ) together with magnesium enriched - $\mathrm{OH}$ allowed the composite to efficiently adsorb RhB. The adsorption capacities of other adsorbents for RhB are listed in Table 1. Comparatively, the magnesium silicate/carbon composite had good adsorption capacity. The adsorption mechanisms of the composite for rhodamine B are shown in Fig. 6. The surface area and pore structure, electrostatic interaction and functional groups were the main adsorption mechanisms.

\subsection{Adsorption kinetics}

Fig. 7 shows the adsorption kinetics that reflect the relation between the adsorption capacity and time at a temperature of $303 \mathrm{~K}$ and $\mathrm{RhB}$ concentration of $400 \mathrm{mg} \mathrm{L}^{-1}$. As shown in figure, the adsorption of RhB initially increased rapidly, followed by

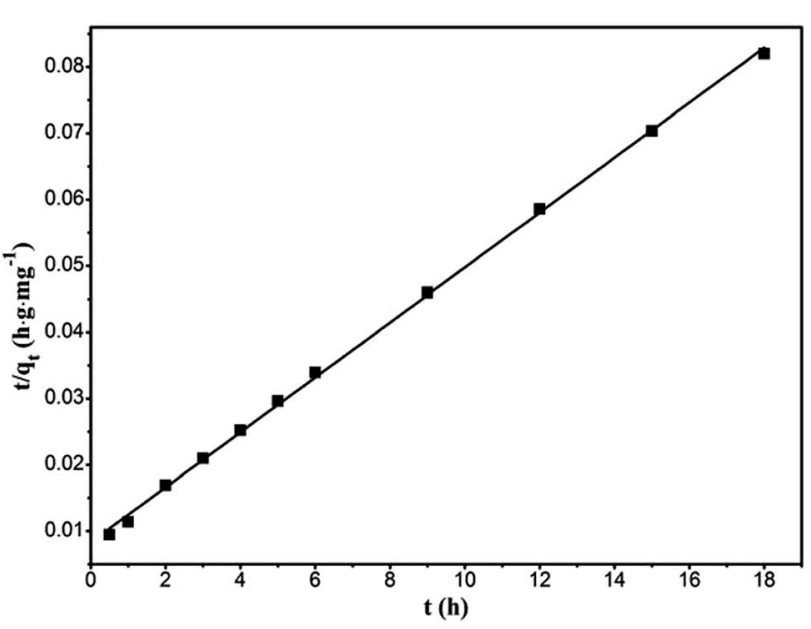

B

Fig. 8 Pseudo-first-order kinetic model plot (A) and pseudo-second-order kinetic model plot (B) of the adsorption of RhB onto magnesium silicate/carbon composite. 
a gradual increase, eventually attaining an asymptote. The trend agreed well with the basic concepts of mass transfer, wherein the initial high adsorption rate is due to the availability of a large number of active adsorption sites, whereas the reduction in the rate with increase in time can be due to the diffusion resistance to reach the active sites in the interior of the adsorbent. The asymptote corresponded to the state wherein the rates of adsorption and desorption were equal to reach the equilibrium state.

The adsorption kinetics can be described by a pseudo firstorder kinetic model (eqn (3)) $)^{\mathbf{4 1}}$ or a pseudo second-order kinetic model (eqn (4)). ${ }^{42}$

$$
\begin{gathered}
\ln \left(q_{\mathrm{e}}-q_{t}\right)=\ln q_{\mathrm{e}}-k_{1} t \\
t / q_{t}=1 / k_{2} q_{\mathrm{e}}^{2}+t / q_{\mathrm{e}}
\end{gathered}
$$

where $q_{\mathrm{e}}\left(\mathrm{mg} \mathrm{g}^{-1}\right)$ and $q_{t}\left(\mathrm{mg} \mathrm{g}^{-1}\right)$ are the adsorptions of RhB onto the composite at equilibrium and time $t(\mathrm{~h})$, respectively. $k_{1}\left(\mathrm{~h}^{-1}\right)$ and $k_{2}\left(\mathrm{~g} \mathrm{mg}^{-1} \mathrm{~h}^{-1}\right)$ are the pseudo-first-order and pseudo-second-order adsorption rate constants, respectively.

The kinetic constants, $k_{1}$ and $k_{2}$ can be calculated from the intercept and slope of the straight lines of $\ln \left(q_{\mathrm{e}}-q_{t}\right) v s . t$ and $t$ / $q_{t} v s$. $t$, respectively (Fig. 8). The corresponding kinetic parameters are listed in Table 2 . The higher $R^{2}$ and $q_{\mathrm{e}}$ closer to saturation adsorption capacity validate the suitability of the pseudosecond-order kinetic model.

For the solid-liquid phase adsorption process, the rate control step can be either external diffusion controlled or intraparticle-diffusion controlled or both. Assuming that the diffusion is intraparticle-diffusion controlled and that it conforms to the Fick's law of diffusion, it has to satisfy eqn (5) according to the Weber and Morris theory. ${ }^{43}$ Fig. 9 shows the relationship between $q_{t}$ and $t^{0.5}$. The plot can be divided into two linear parts. The first linear part has a high slope, which indicates that the adsorption is external diffusion controlled, whereas the second linear portion has a low slope, which indicates that the adsorption is intraparticle-diffusion controlled.

$$
q_{t}=K_{\mathrm{id}} t^{0.5}
$$

To predict the rate control step in the adsorption process, the kinetic data are further analyzed using the Boyd kinetic equation (eqn (6), (7)). ${ }^{44}$

$$
\begin{gathered}
B_{t}=-0.4977-\ln (1-F) \\
F=q_{t} / q_{\mathrm{e}}
\end{gathered}
$$

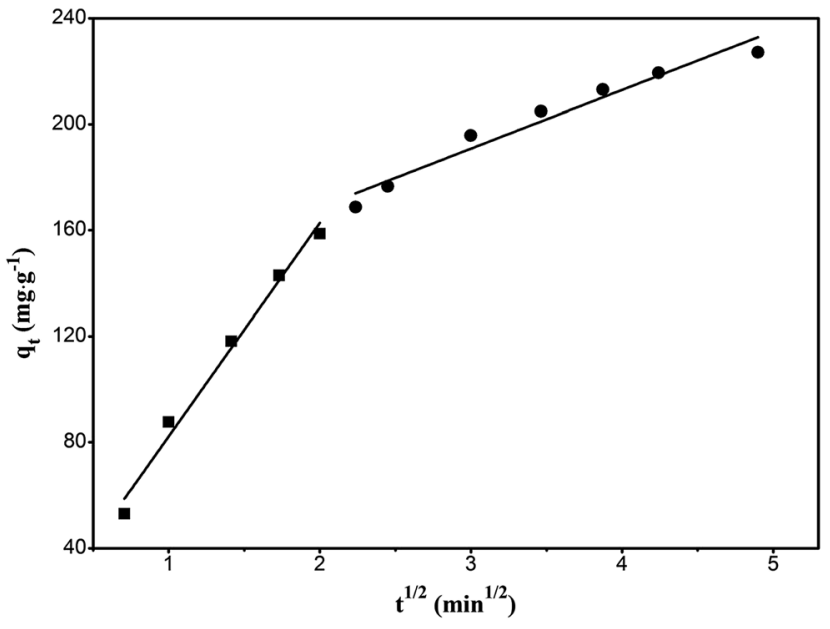

Fig. 9 Intraparticle-diffusion model plot of the adsorption of RhB onto magnesium silicate/carbon composite.

where $F$ is the ratio of the amount of adsorption to the equilibrium adsorption capacity at time $t$.

Fig. 10 is the plot of $B_{t}$ against $t$, which can distinguish whether the adsorption belongs to external diffusion or intraparticle-diffusion control. If the line passes through the origin, it indicates that the adsorption is intraparticle-diffusion controlled, otherwise it is external diffusion controlled. It can be seen from the figure that the intercept of the straight line on the $y$-axis approximately passes through the origin, proving that the adsorption is intraparticle-diffusion controlled.

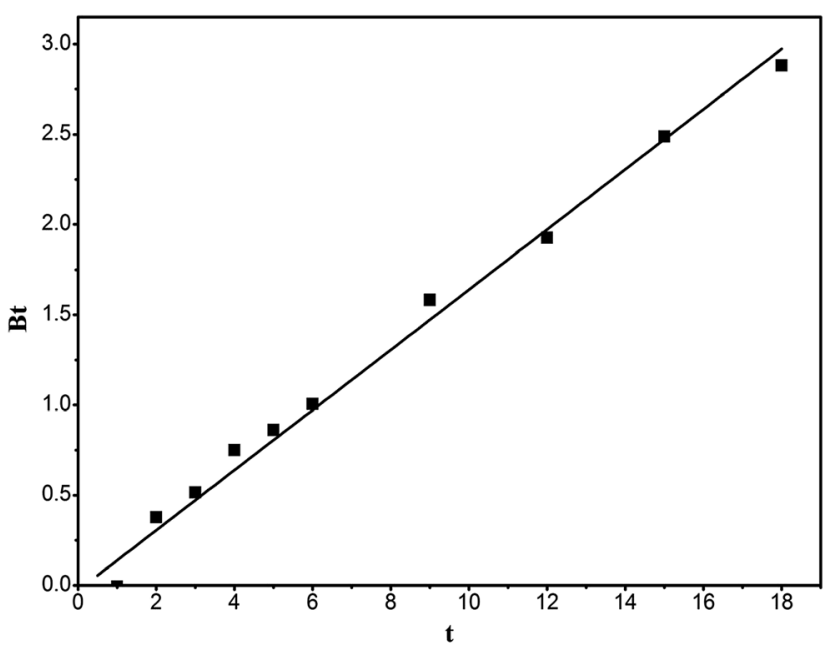

Fig. $10 B_{t}$ vs. $t$ curve of the adsorption of RhB onto magnesium silicate/carbon composite.

Table 2 Kinetic parameters of the adsorption of RhB onto magnesium silicate/carbon composite

\begin{tabular}{lllllll}
\hline & \multicolumn{2}{l}{ Pseudo first-order model } & & \multicolumn{2}{c}{ Pseudo second-order model } \\
\cline { 2 - 3 }$q_{\exp }\left(\mathrm{mg} \mathrm{g}^{-1}\right)$ & $q_{\mathrm{e}}\left(\mathrm{mg} \mathrm{g}^{-1}\right)$ & $k_{1}\left(\mathrm{~h}^{-1}\right)$ & $R^{2}$ & & $q_{\mathrm{e}}\left(\mathrm{mg} \mathrm{g}^{-1}\right)$ & $k_{2}\left(\mathrm{~g} \mathrm{mg}^{-1} \mathrm{~h}^{-1}\right)$ \\
\hline 227.17 & 152.47 & 0.1661 & 0.9858 & 243.90 & 0.0020 & $R^{2}$ \\
\hline
\end{tabular}




\subsection{Adsorption isotherms}

The adsorption thermodynamics were studied by changing the initial concentration of $\mathrm{RhB}$ in the range of 50 to $600 \mathrm{mg} \mathrm{L}^{-1}$ at 303 K. As shown in Fig. 11, the adsorption of RhB onto the composite increased with the increase in the initial concentration until it approached the saturation adsorption at the initial concentration of $600 \mathrm{mg} \mathrm{L}^{-1}$.

Adsorption isotherms can help to understand the adsorption mechanism. The adsorption isotherm data were tested with the Langmuir isotherm model (eqn (8)) $)^{45}$ and the Freundlich isotherm model (eqn (9)) ${ }^{46}$ to identify the appropriate model.

$$
\begin{gathered}
q_{\mathrm{e}}=K_{\mathrm{L}} C_{\mathrm{e}} /\left(1+a_{\mathrm{L}} C_{\mathrm{e}}\right) \\
q_{\mathrm{e}}=a_{\mathrm{f}} C_{\mathrm{e}}^{b_{\mathrm{f}}}
\end{gathered}
$$

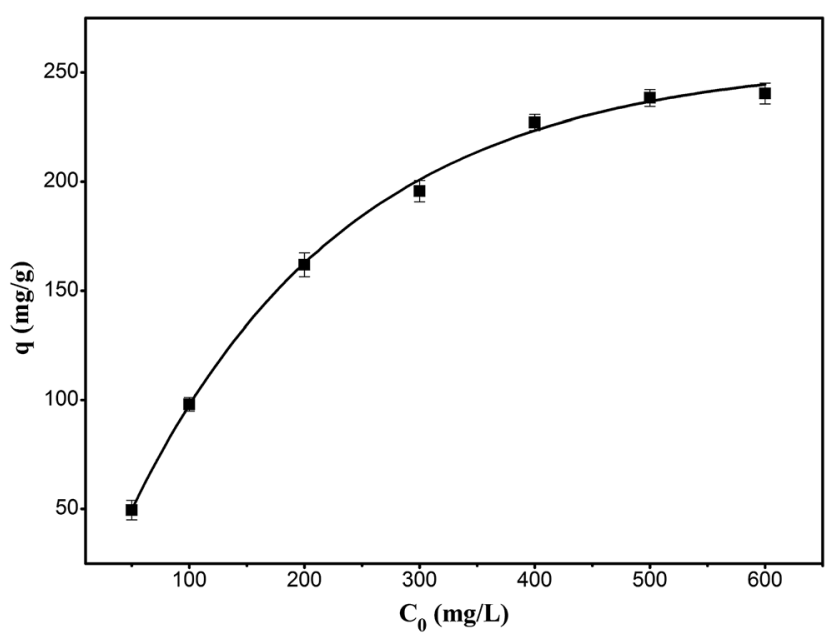

Fig. 11 Effect of initial concentration of RhB for the adsorption of RhB onto magnesium silicate/carbon composite.

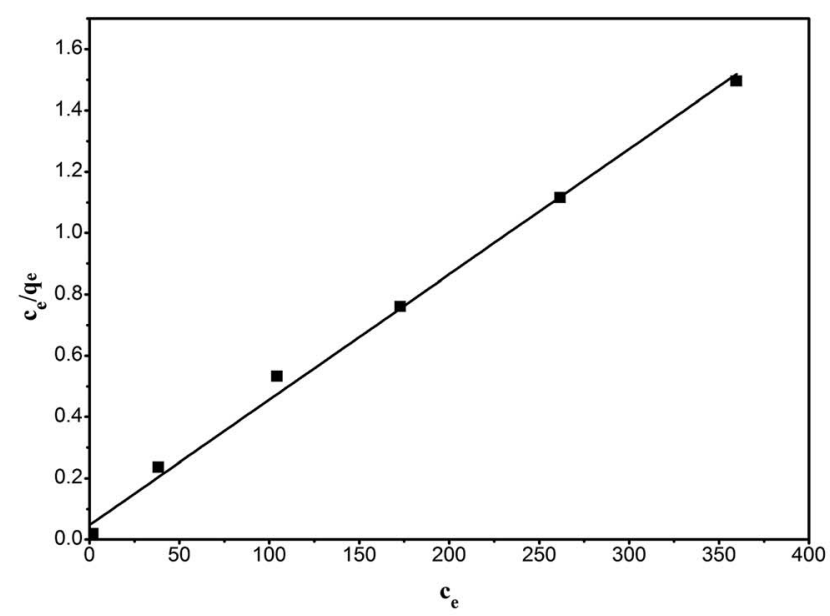

A where $q_{\mathrm{e}}\left(\mathrm{mg} \mathrm{g}^{-1}\right)$ and $C_{\mathrm{e}}\left(\mathrm{mg} \mathrm{L}^{-1}\right)$ are the adsorption capacity of the adsorbent for $\mathrm{RhB}$ and the concentration of $\mathrm{RhB}$ in the aqueous solution at equilibrium, respectively. $K_{\mathrm{L}}\left(\mathrm{L} \mathrm{g} \mathrm{g}^{-1}\right)$ and $a_{\mathrm{L}}$ $\left(\mathrm{L} \mathrm{mg}^{-1}\right)$ are Langmuir constants. $a_{\mathrm{f}}$ is the Freundlich constant, and $b_{\mathrm{f}}$ is the component factor.

The linear plots of the Langmuir model (Fig. 12A) and the Freundlich model (Fig. 12 B) were obtained by plotting $C_{\mathrm{e}} / q_{\mathrm{e}}$ versus $c_{\mathrm{e}}$ and $\ln \left(q_{\mathrm{e}}\right)$ versus $\ln \left(c_{\mathrm{e}}\right)$, and the model parameters along with the goodness of the model fit are shown in Table 3. The Langmuir model described the adsorption behavior of RhB on the composite better than did the Freundlich equation, evidenced from the high correlation coefficients $\left(R^{2}=0.9959\right)$. This proved that the adsorption was monolayer adsorption. The adsorption kinetics and isotherms results obtained in this study were consistent with those reported in the literature. ${ }^{28,30}$

Additionally, the thermodynamic parameters of the adsorption reaction were calculated. The standard Gibbs free energy $\Delta G^{0}$ was calculated by eqn (10) and (11), and the standard enthalpy $\Delta H^{0}$ and the standard entropy change $\Delta S^{0}$ were calculated by the Van't Hoff equation (eqn (12)).

$$
\begin{gathered}
\Delta G^{0}=-R T \ln K_{\mathrm{c}} \\
K_{\mathrm{c}}=C_{\mathrm{Be}} / C_{\mathrm{Ae}} \\
\ln K_{\mathrm{c}}=\Delta S^{0} / R-\Delta H^{0} / R T
\end{gathered}
$$

Table 3 Langmuir and Freundlich isotherms of the adsorption of RhB onto magnesium silicate/carbon composite

\begin{tabular}{llllllll}
\hline \multicolumn{2}{l}{ Langmuir model } & & & \multicolumn{3}{l}{ Freundlich model } \\
\cline { 1 - 2 } \cline { 5 - 6 }$K_{\mathrm{L}}\left(\mathrm{L} \mathrm{g}^{-1}\right)$ & $a_{\mathrm{L}}\left(\mathrm{L} \mathrm{mg}^{-1}\right)$ & $R^{2}$ & & $a_{\mathrm{f}}$ & $b_{\mathrm{f}}$ & $R^{2}$ \\
\hline 21.14 & 0.0867 & 0.9959 & 60.67 & 0.2473 & 0.8831
\end{tabular}

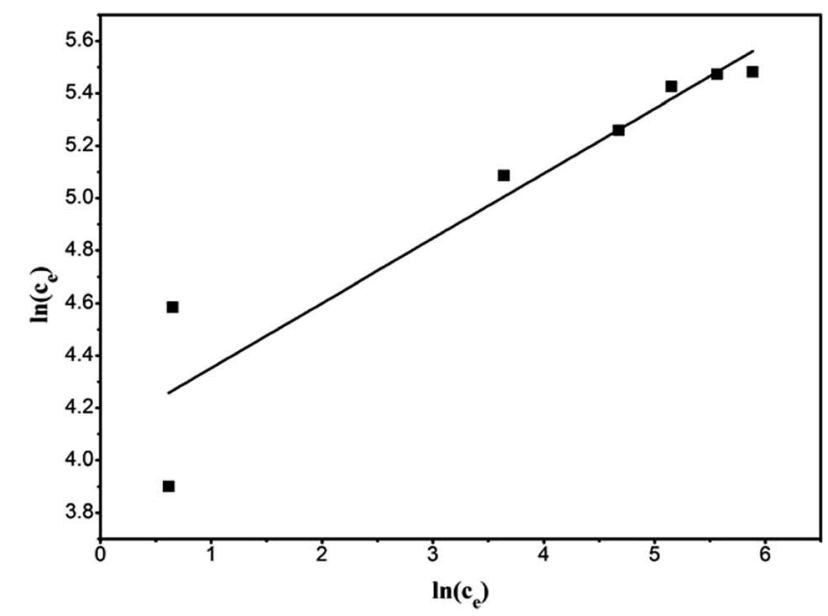

B

Fig. 12 Equilibrium isotherms of the adsorption of RhB onto magnesium silicate/carbon composite: Langmuir isotherm (A) and Freundlich isotherm (B). 


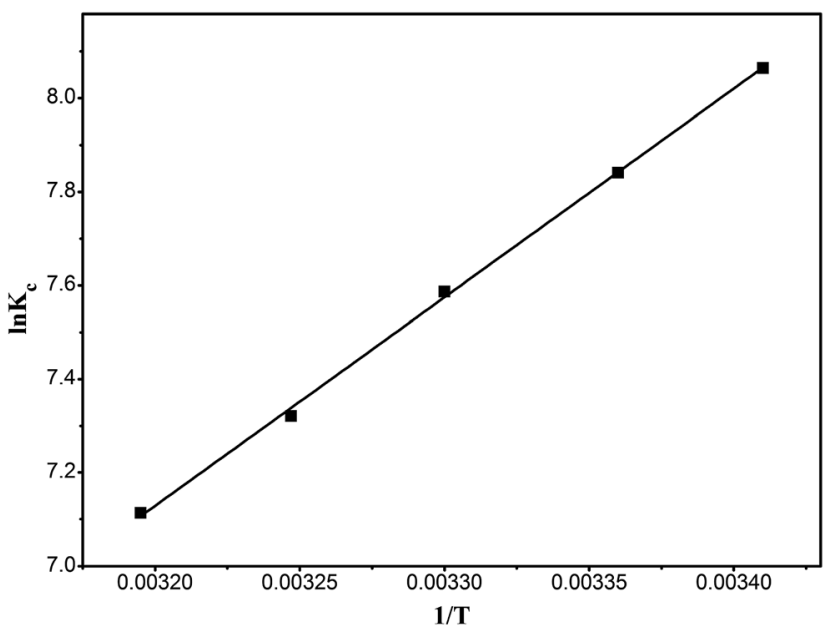

Fig. 13 Van't Hoff curve of the adsorption of RhB onto magnesium silicate/carbon composite.

Table 4 Thermodynamic parameters of the adsorption of RhB onto magnesium silicate/carbon composite

\begin{tabular}{llll}
\hline$T(\mathrm{~K})$ & $\begin{array}{l}\Delta G^{0} \\
\left(\mathrm{KJ} \mathrm{mol}^{-1}\right)\end{array}$ & $\begin{array}{l}\Delta H^{0}(\mathrm{KJ} \\
\left.\mathrm{mol}^{-1}\right)\end{array}$ & $\begin{array}{l}\Delta S^{0}(\mathrm{~J} \\
\left.\mathrm{mol}^{-1} \mathrm{~K}^{-1}\right)\end{array}$ \\
\hline 293 & -19.8354 & -37.46 & -60.64
\end{tabular}

where $C_{\mathrm{Ae}}$ and $C_{\mathrm{Be}}\left(\mathrm{mg} \mathrm{L}^{-1}\right)$ and $\left(\mathrm{mg} \mathrm{L}^{-1}\right)$ are the concentrations of the adsorbate in the solution and solid phase, respectively. $R$ is the thermodynamic constant.

Fig. 13 is a plot of $\ln K_{\mathrm{c}}$ versus $1 / T$, and the calculated results are shown in Table 4 . The $\Delta H^{0}$ value of $-37.46 \mathrm{~kJ} \mathrm{~mol}^{-1}$ and the $\Delta G^{0}$ of -19.8354 to $-18.5116 \mathrm{~kJ} \mathrm{~mol}^{-1}$ show that the adsorption of $\mathrm{RhB}$ onto the composite is a spontaneous exothermic reaction.

\section{Conclusions}

In this study, the preparation, characterization and adsorption of $\mathrm{RhB}$ for the magnesium silicate/carbon composite were carried out. The equilibrium adsorption capacity of the composite was found to be $244 \mathrm{mg} \mathrm{g}^{-1}, 27.48 \%$ higher than that of magnesium silicate. The adsorption of $\mathrm{RhB}$ onto the composite was affected by the $\mathrm{pH}$ of the solution with the highest adsorption capacity corresponding to a pH of 9. FT-IR spectra analysis proved that the composite of magnesium silicate and hydrothermal carbon could be successfully realized with the presence of $-\mathrm{OH}$ and $-\mathrm{COOH}$ functional groups for adsorption. XRD analysis showed that the magnesium silicate/ carbon composite was in an amorphous state, whereas the morphology and pore structure analysis indicated that the magnesium silicate/carbon composite was porous. Adsorption kinetics showed that the pseudo-second-order kinetic model was more suitable for describing the adsorption kinetics, and the adsorption rate control step was intraparticle-diffusion. The adsorption isotherms could be modeled using the Langmuir isotherm model, confirming the adsorption to be monolayer adsorption. Thermodynamic parameters showed that the adsorption process was a spontaneous exothermic reaction. Briefly, surface area and pore structure, electrostatic interaction and functional groups were identified to be major contributors for the increase in adsorption capacity. Considering the simplicity of the process to synthesize magnesium silicate/ carbon composite, it could serve to be a cost-effective adsorbent to treat wastewater streams with organic dyes.

\section{Conflicts of interest}

There are no conflicts to declare.

\section{Acknowledgements}

This study described above was financially supported by the National Key R\&D Program of China (No. 2017YFB0310805).

\section{References}

1 F. Li, J. Huang, Q. Xia, M. Lou, B. Yang, Q. Tian and Y. Liu, Sep. Purif. Technol., 2018, 195, 83-91.

2 A. M. Lotito, M. De Sanctis, C. Di Iaconi and G. Bergna, Water Res., 2014, 54, 337-346.

3 X. Ma, P. Chen, M. Zhou, Z. Zhong, F. Zhang and W. Xing, Ind. Eng. Chem. Res., 2017, 56, 7070-7079.

4 C. S. D. Rodrigues, L. M. Madeira and R. A. R. Boaventura, Ind. Eng. Chem. Res., 2013, 52, 13313-13324.

5 G. Bharath, E. Alhseinat, N. Ponpandian, M. A. Khan, M. R. Siddiqui, F. Ahmed and E. H. Alsharaeh, Sep. Purif. Technol., 2017, 188, 206-218.

6 Y. Liu, J. Xie, C. N. Ong, C. D. Vecitis and Z. Zhou, Environ. Sci.: Water Res. Technol., 2015, 1, 769-778.

7 P. Luo, Y. Zhao, B. Zhang, J. Liu, Y. Yang and J. Liu, Water Res., 2010, 44, 1489-1497.

8 H. S. Rai, M. S. Bhattacharyya, J. Singh, T. K. Bansal, P. Vats and U. C. Banerjee, Crit. Rev. Environ. Sci. Technol., 2005, 35, 219-238.

9 K. Li, Y. He, Y. L. Xu, Y. L. Wang and J. P. Jia, Environ. Sci. Technol., 2011, 45, 7401-7407.

$10 \mathrm{H}$. Wu, Z. Liu, A. Li and H. Yang, Chemosphere, 2017, 174, 200-207.

11 S. Kakarndee and S. Nanan, J. Environ. Chem. Eng., 2018, 6, 74-94.

12 P. R. Gogate and A. B. Pandit, Adv. Environ. Res., 2004, 8, 553597.

13 M. Mohammadi, A. J. Hassani, A. R. Mohamed and G. D. Najafpour, J. Chem. Eng. Data, 2010, 55, 5777-5785.

14 O. Turgay, G. Ersoz, S. Atalay, J. Forss and U. Welander, Sep. Purif. Technol., 2011, 79, 26-33.

15 X. Li, J. Xu, J. Cheng, L. Feng, Y. Shi and J. Ji, Sep. Purif. Technol., 2017, 187, 303-310.

16 N. Zhou, H. Chen, J. Xi, D. Yao, Z. Zhou, Y. Tian and X. Lu, Bioresour. Technol., 2017, 232, 204-210.

17 Z. Huang, Y. Li, W. Chen, J. Shi, N. Zhang, X. Wang, Z. Li, L. Gao and Y. Zhang, Mater. Chem. Phys., 2017, 202, 266-276. 
18 E. Menya, P. W. Olupot, H. Storz, M. Lubwama and Y. Kiros, Chem. Eng. Res. Des., 2018, 129, 271-296.

19 R. Llia, L. Liatsou, L. Sawa, E. Vasile, L. Vekas, O. Marinica, F. Mpekris, I. Pashalidis and T. Krasia-Christoforou, Eur. Polym. J., 2017, 97, 138-146.

20 M. Parolo, M. Avena, G. Pettinari and M. Baschini, J. Colloid Interface Sci., 2012, 368, 420-426.

21 L. Qin, S. Zhang, Y. Zhang, T. Cao, J. Zhao and Z. Guo, Instrum. Sci. Technol., 2014, 42, 357-367.

22 W. Wang, G. Tian, L. Zong, Y. Zhou, Y. Kang, Q. Wang and A. Wang, J. Environ. Sci., 2017, 51, 31-43.

23 Q. Lu, Q. Li, J. Zhang, J. Li and J. Lu, Appl. Surf. Sci., 2016, 360, 889-895.

24 F. Ciesielczyk, A. Krysztafkiewicz and T. Jesionowski, Appl. Surf. Sci., 2007, 253, 8435-8442.

25 G. Tian, W. Wang, L. Zong, Y. Kang and A. Wang, Chem. Eng. J., 2016, 293, 376-385.

26 S. Lu, J. Hu, C. Chen, X. Chen, Y. Gong, Y. Sun and X. Tan, Sep. Purif. Technol., 2017, 174, 425-431.

27 X. Zhang, L. Cheng, X. Wu, Y. Tang and Y. Wu, J. Environ. Sci., 2015, 33, 97-105.

28 Z. Cheng, Y. Li and Z. Liu, J. Ind. Eng. Chem., 2017, 55, 234243.

29 P. Xiao, L. Zhao, Z. Sui, M. Xu and B. Han, Microporous Mesoporous Mater., 2017, 253, 215-222.

30 X. Wu, Y. Xu, X. Zhang, Y. Wu and P. Gao, New Res. Carbon Mater., 2015, 30, 71-78.

31 T. Xiong, X. Yuan, X. Chen, Z. Wu, H. Wang, L. Leng, H. Wang, L. Jiang and G. Zeng, Appl. Surf. Sci., 2018, 427, 1107-1117.
32 M. T. Yagub, T. K. Sen, S. Afroze and H. M. Ang, Adv. Colloid Interface Sci, 2014, 209, 172-184.

33 F. Hayeeye, M. Sattara, W. Chinpab and O. Sirichotea, Colloids Surf., A, 2017, 513, 259-266.

34 Z. Cheng, Y. Li and Z. Liu, J. Alloys Compd., 2017, 708, 255263.

35 X. Jiang and J. Huang, J. Colloid Interface Sci., 2016, 467, 230238.

36 M. Ptaszkowska-Koniarz, J. Goscianska and R. Pietrzak, J. Colloid Interface Sci., 2017, 504, 549-560.

37 K. Liu, H. Li, Y. Wang, X. Gou and Y. Duan, Colloids Surf., A, 2015, 477, 35-41.

38 M. Sattar, F. Hayeeye, W. Chinpa and O. Sirichote, J. Environ. Chem. Eng., 2017, 5, 3780-3791.

39 F. Motahari, M. R. Mozdianfard and M. Salavati-Niasari, Process Saf. Environ. Prot., 2015, 93, 282-292.

40 S. Wang, B. Yang and Y. Liu, J. Colloid Interface Sci., 2017, 507, 225-233.

41 Y. Chang, H. Liu and F. Zha, Chem. Eng. J., 2011, 167, 183189.

42 G. Mckay and Y. S. Ho, Process Biochem., 1999, 34, 451-465.

43 W. J. Weber and J. C. Morris, J. Sanit. Eng. Div., Am. Soc. Civ. Eng., 1963, 89, 31-60.

44 G. E. Boyd, A. W. Adamson and L. S. Myers, J. Am. Chem. Soc., 1947, 69, 2836-2848.

45 I. Langmuir, J. Am. Chem. Soc., 1918, 40, 1361-1403.

46 H. M. F. Freundlich, J. Phys. Chem., 1906, 57, 385-470. 